\title{
EVOLUÇÃO GEOLÓGICA DOS GRUPOS CANASTRA E IBIÁ NA REGIÃO ENTRE COROMANDEL E GUARDA-MOR, MG
}

\author{
Luciana Felício Pereira*, Marcel Auguste Dardenne**, Carlos Alberto Rosière*** \\ \& Antônio Carlos Pedrosa-Soares ***
}

\begin{abstract}
The stratigraphic column established for the Canastra Group, in the Alto Paranaíba region in the central portion of the Brasília Fold Belt, represents a regressive megasequence of sediments deposited on an opensea continental platform. The following units occur from base to top: a turbiditic sequence with arenaceous and argillaceous intercalations; an arenaceous sequence containing storm beds; and a clay-rich arenaceous sequence with structures reflecting shallow marine and tidal flat environments. The Ibiá Group overlies the Canastra Group on an erosional disconformity. Its base consists of a metadiamictite of glacial origin (Cubatão Formation) while the uppermost unit (Rio Verde Formation) comprises an extensive and monotonous package of banded calcareous phyllites. The contact between these two formations is gradational and both units have similar mineralogic composition. The Canastra and Ibiá Groups were affected by a single event of progressive deformation, $\mathrm{E}_{1}$, during the Brasiliano Cycle, manifested as two distinct compressional stages. The earliest and most compressive stage, $\mathrm{D}_{1}$, is represented by thrust tectonics, associated with greenschist facies metamorphism. The second stage of deformation, $\mathrm{D}_{2}$, is characterized by a dominant component of pure shear in a ductile-brittle regime. When compared with other similar units in the geochronological record, the characteristics of the studied units show that the Ibiá Group metadiamictites are contemporaneous with the Jequitaí tillite, with a probable age of deposition between 900 and $1000 \mathrm{Ma}$ and the Canastra Group is therefore older than $1000 \mathrm{Ma}$.
\end{abstract}

Palavras-chave: Faixa Brasília, Glaciação Proterozóica, Grupo Canastra, Grupo Ibiá.

\section{INTRODUÇÃO}

A região estudada localiza-se no cinturão de dobramentos da borda ocidental do Craton São Francisco, a Faixa Brasília (Figs. 1 e 6).

Devido a grande extensão territorial ocupada por esta faixa de dobramento, grande parte dos trabalhos aí desenvolvidos até a década de 70 , foram de cunho regional muito amplo, favorecendo o agrupamento de unidades distintas e dificultando sua interpretacão evolutiva.

Hasui \& Almeida (1970) e Almeida et al. (1976), definiram duas faixas dobradas distintas: a Faixa de Dobramentos Brasília, do Proterozóico Superior (Ciclo Brasiliano), que desenvolveu-se paralelamente à Faixa de Dobramento Uruaçu, atribuida ao Proterozóico Médio (Ciclo Uruaçuano).

Esta estruturação foi mantida ao longo dos anos por grande parte dos autores que estudaram a região, sugerindo adaptações de acordo com o surgimento de novas teorias e com a evolução do conhecimento sobre a região. Dentre outros autores, destacam-se Almeida (1968, 1977), Almeida et al. (1977), Mariniet al. (1981, 1984), Fuck \& Marini (1981), Dardenne (1981), Dardenne et al. (1978), Cordani \& Brito Neves (1982), Haralyi \& Hasui (1982).

Outros autores questionaram aquela estruturação, defendendo uma evolução monocíclica: Costa \& Angeiras (1971), Dardenne (1978, 1979), Campos Neto (1979), Heilbron et al. (1987), Pimentel et al. (1992), Chemale Jr. et al. (1991), Brito Neves \& Cordani (1991).

\section{LITO-ESTRATIGRAFIA}

As unidades aqui apresentadas são referidas na literatura geológica em diferentes níveis de hierarquia e posicionamento lito-estratigráficos. Com base nos dados apresentados e na normatização dada pelo Código Brasileiro de Nomenclatura Estratigráfica (Petri et al. 1986), discutiremos a classificação litoestratigráfica para estas unidades (vide Pereira 1992).

A "Formação Canastra" foi definida por Barbosa (1955), na região da Serra da Canastra, sendo constituida por quartzitos e filitos diversos. Foi considerada mais jovem do que o Grupo Araxá e posicionada sobre este, em decorrência de uma discordância do tipo "não conformidade", materializada sobretudo por uma diferença de grau metamórfico.

Durante as décadas de 60 e 70 os domínios destas duas unidades foram estendidos para a região do Planalto Central Brasileiro, sendo comum autores expressarem dificuldades em individualizá-las, classificando-as ora como grupo ora como formação.

Optou-se pela designação Grupo Canastra (Almeida 1967), independente da unidade Araxá, por ser possível a individualização de três subunidades mapeáveis, informalmente denominadas de formações basal, intermediária e superior. A seção-tipo desta unidade é encontrada na estrada que corta o Chapadão dos Pilões,próximo a cidade de Guarda-Mor, podendo a sequência completa atingir cerca de $2.000 \mathrm{~m}$ de espessura(Pereira 1992).

As rochas que constituem a "Formação" Ibiá, foram 


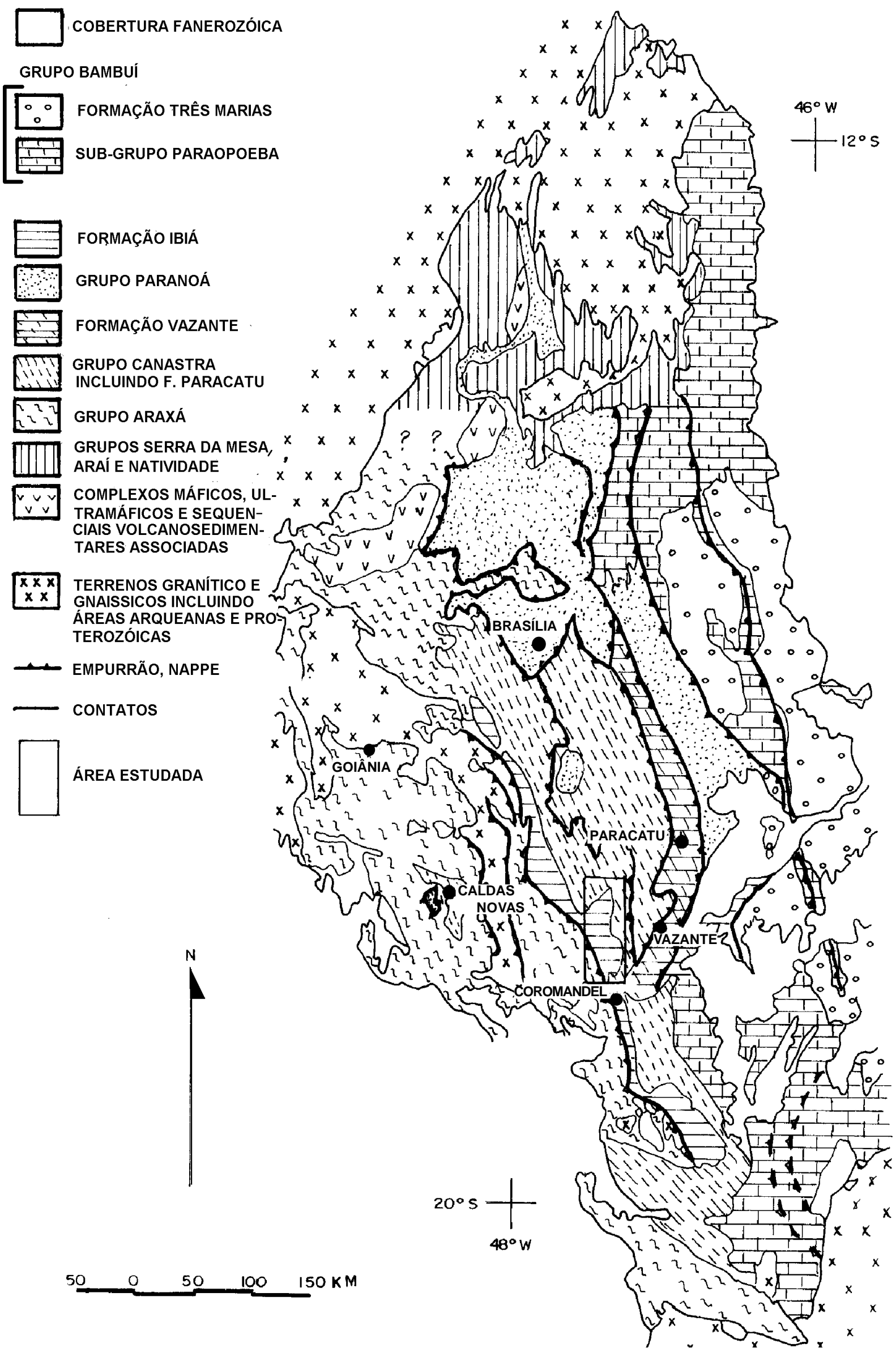

Figura 1: Contexto geotectônico da região estudada, no âmbito da Faixa Brasília (adaptado de Fuck et al. 1993) Figure 1: Geotectonic context of the studied area within the Brasilia Belt (modified from Fuck et al. 1993). 
descritas pela primeira vez por Barbosa et al. (1970), tendo como seção-tipo a pedreira da cidade de Ibiá, no alto Rio Quebra Anzol, MG.

Estes autores, a princípio, posicionaram a unidade constituida por calcixistos na base do Grupo Canastra, considerando os xistos do Grupo Araxá sempre cavalgantes sobre ela. Contudo, em nota adicional no mesmo trabalho, referem-se ao carater "formacional" da unidade Ibiá, evidenciado pela ocorrência de um metaconglomerado no contato com o Grupo Canastra, ao qual estaria, então, sobreposta.

A importante discordância erosiva identificada entre esta unidade e o Grupo Canastra e suas características sedimentares peculiares são suficientes para justificar a individualização da unidade Ibiá com relação aos grupos Canastra e Araxá. Os dois litotipos Ibiá apresentam características petrográficas e sedimentológicas distintas, espessuras de centenas de metros e continuidade lateral de quase uma centena de quilômetros, podendo ser, portanto, definidos como formações. Desta maneira, a unidade Ibiá alcança a categoria hierárquica de Grupo Ibiá, tendo sido dividido em duas formações por Pereira (1992): Formação Cubatão, conglomerática, na base e Formação Rio Verde, filítica, no topo. As melhores exposições do Grupo Ibiá localizam-se nos vales do Rio Verde e dos seus afluentes, em especial nos córregos Cubatão e da Corda, sendo a espessura máxima aparente superior a $2.000 \mathrm{~m}$.

\section{Grupo Canastra}

O Grupo Canastra apresenta-se como um conjunto de intercalações, mais ou menos espessas, de filitos e quartzitos. $\mathrm{O}$ contato basal da sequência se faz através de falha de cavalgamento, posicionando o Grupo Canastra sobre as rochas metapelíticas das formações Vazante e Paracatu. O contato superior, com o paraconglomerado basal da Formação Ibiá, caracterizase como discordância erosiva.

A espessura média da sequência de filitos e quartzitos varia consideravelmente desde a porção norte, onde sustenta chapadões de grande extensão, até a porção sul, onde parece ter ocorrido encurtamento crustal por força da tectônica compressiva imposta à área. A sequência completa pode atingir cerca de $2.000 \mathrm{~m}$ de espessura.

O conjunto compreende uma sequência iniciada por filitos que, em direção ao topo, apresentam aumento progressivo da contribuição arenosa, passando a quartzo-filitos, quartzitos micáceos, quarzitos e finalmente aos ortoquartzitos que sustentam as escarpas das serras e os chapadões.

Toda a sequência apresenta uma gradação lateral e vertical entre pacotes de filito e quartzito. Cada pacote, internamente, apresenta a mesma gradação em escala menor, evidenciando uma ritmicidade do conjunto.

Esta variação faciológica dificulta o estabelecimento de uma coluna litoestratigráfica única para a área, pois no sul, a sequência rítmica é constituída por uma sucessão gradativa de filitos até os ortoquartzitos superiores, enquanto no norte, a mesma sequência apresenta níveis expressivos de filitos próximo ao topo (Fig. 2).

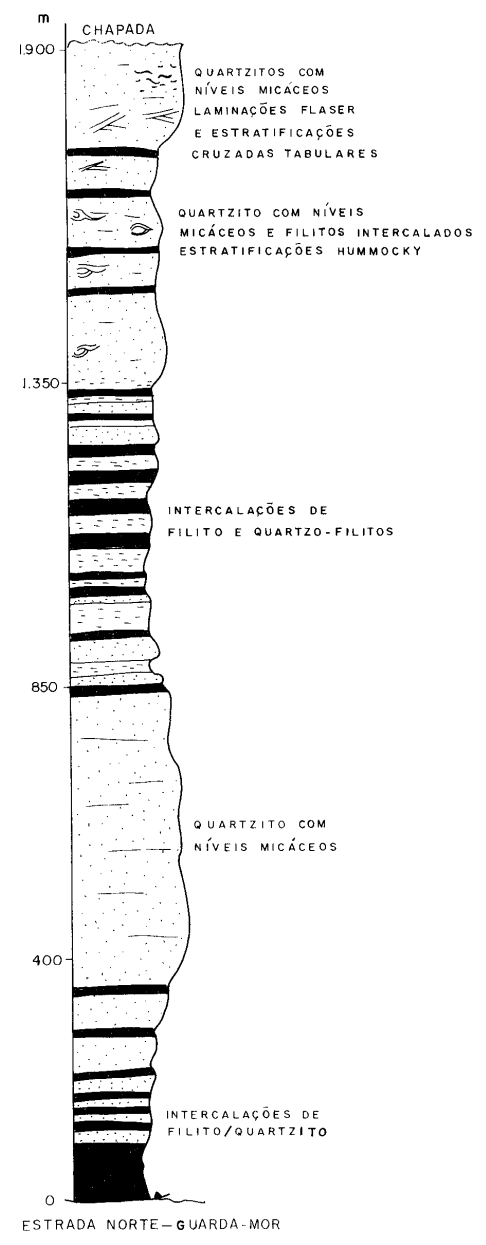

Figura 2: Coluna lito-estratigráfica do Grupo Canastra entre Coromandel e Guarda-Mor.

Figure 2: Lithostratigraphic column of the Canastra

Group between Coromandel and Guarda-Mor.

Os filitos e quartzo-filitos se caracterizam por coloração prateada quando frescos, passando a avermelhados quando intemperizados e localmente, ocorrem níveis decimétricos de quartzo micáceo e ortoquartzito fino.

O pacote de quartzitos compreende desde quartzitos micáceos laminados até ortoquartzitos maciços, sendo comuns intercalações de níveis centimétricos de cloritamuscovita filito em quase todos os estratos. Em geral, os quartzitos apresentam granulometria fina à média. Podem ocorrer, ainda, quartzitos hematíticos finos associados à porção superior da sequência e quartzitos de granulometria média com piritas euédricas de até $0,5 \mathrm{~cm}$.

A composição mineralógica de todas estas rochas é basicamente a mesma, diferenciando-se pela porcentagem de quartzo e filossilicatos. Quantitativamente, a contribuição de quartzo situa-se em torno de $20 \%$ para os filitos e de 20 a $50 \%$ para os quartzo filitos. As rochas contendo 50 a $25 \%$ de filossilicatos foram denominadas quartzitos micáceos, 
entre 25 e $5 \%$ quartzitos e como ortoquartzito, aquelas com menos de $5 \%$ de micas e clorita.

A mineralogia essencial é constituída por quartzo, sericita, muscovita, clorita e plagioclásio. O plagioclásio raramente ultrapassa $5 \%$ da composição da rocha e invariavelmente, apresenta alterações para sericita e carbonato. Os minerais acessórios são opacos, zircão, turmalina e rutilo, geralmente com formas arredondadas, atestando origem detrítica. $\mathrm{O}$ rutilo quase sempre está leucoxenizado e alguns cristais euédricos de turmalina e pirita aparecem como minerais neoformados.

O metamorfismo no Grupo Canastra é do tipo regional de baixo grau, na fácies xisto verde, zona da clorita. A paragênese mineral é formada pelos minerais quartzo + sericita/muscovita + clorita (+ pirita).

Estruturas sedimentares encontram-se melhor preservadas na porção norte da área, onde a deformação apresenta-se com menor intensidade. A sul, estas estruturas foram totalmente obliteradas pela deformação.

Perfis na porção norte da área, acompanhando a unidade desde o contato inferior com a Formação Vazante até os chapadões do topo da serra, mostram importantes estruturas, definindo a melhor coluna litoestratigráfica para a região, que se apresenta a seguir: - a Formação Inferior inicia-se com filitos passando a conter intercalações métricas e sucessivas de filitos e quartzo filitos, sobrepostas por espesso pacote de quartzitos micáceos, recoberto por nova sucessão de filitos e quartzo filitos intercalados.

- quartzitos micáceos compõem a Formação Intermediária, verificando-se estruturas sedimentares do tipo hummocky com comprimento de onda da ordem de $2 \mathrm{~m}$, amplitudes decimétricas e abundantes truncamentos internos com variações na espessura dos estratos.

- estratificações cruzadas tabulares, decimétricas a métricas, com laminações sublinhadas por minerais opacos, são frequentes nas unidades quartzíticas superiores (Formaçào Superior), assim como marcas ondulares. Identificou-se, também, estratificação cruzada invertida, laminações sinuosas do tipo flaser e estruturas de carga do tipo quick sands.

\section{Ambiente de Sedimentação}

A característica fundamental das rochas do Grupo Canastra, é a granocrescência ascendente, verificada na gradação dos estratos argilosos da base, até estratos arenosos nas porções superiores. Estruturas sedimentares associadas, tais como hummocky, estratificações cruzadas e laminações flaser, fortalecem a proposição de um ambiente deposicional em plataforma marinha, durante ciclo regressivo (Fig. 3).

$\mathrm{Na}$ unidade basal, a ocorrência de expressiva camada de filitos seguida de intercalações de filitos e quartzo filitos, sugere deposição argilosa em água profunda, passando para plataforma de declive acentuado, com formação de sequências turbidíticas.

As estruturas tipo hummocky, presentes na unidade intermediária, indicam depósitos gerados durante tempestades, em plataforma marinha, abaixo da zona de influência das correntes de maré (Harms et al. 1982; Duke 1985; Craft \& Bridge 1987).

As estratificações cruzadas e marcas de ondas, descritas nos quartzitos superiores, são estruturas geradas em ambiente dominado pela ação de ondas e de correntes de marés, enquanto as laminações flaser, presentes próximo ao topo da sequência, são estruturas características de planícies de marés.(Reineck \& Singh 1973; Walker et al. 1984).

\section{Grupo Ibiá}

Formação Cubatão

Diretamente sobreposto aos ritmitos de filitos e quartzitos do Grupo Canastra, com marcada discordância erosiva, repousam os paraconglomerados da base do Grupo Ibiá, englobados na Formação Cubatão (Pereira 1992).

As melhores exposições estão presentes na parte norte, enquanto a sul estas se apresentam bastante intemperizadas e com espessura reduzida. A espessura

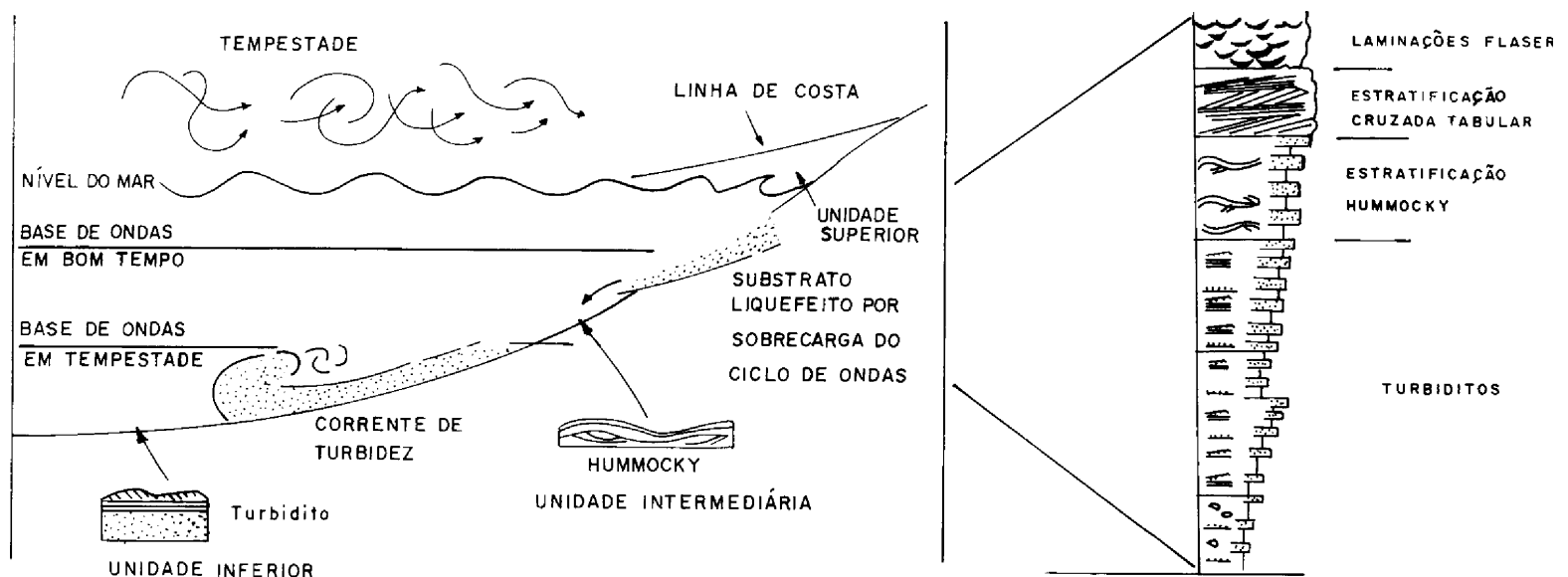

Figura 3: Modelo de ambiente de sedimentação para o Grupo Canastra (modificado de Walker 1984)

Figure 3: Conceptual and schematic model of sedimentary environment of the Canastra Group (adapted from Walker 1984). 
máxima aparente, estimada na região do Córrego da Corda, próximo à cidade de Guarda-Mor, é de algumas centenas de metros.

Trata-se de uma rocha com abundante matriz de composição metapelito-carbonatada, na qual flutuam fragmentos de diferentes tamanhos, formas e litologias.

Estes fragmentos variam desde grânulos até matacões com mais de $1 \mathrm{~m}$ de comprimento ao longo de seu eixo maior. Aqueles constituídos por litologias mais resistentes mostram formas de baixa esfericidade, facetados e até mesmo, forma pentagonal. Outros de menor competência encontram-se deformados juntamente com a matriz, mostrando formas alongadas. Alguns seixos de quartzitos apresentam estrias. Fragmentos de quartzo e quartzito são predominantes, mas ocorrem, também, aqueles derivados de rochas graníticas, rochas básicas, filito, calcário, chert e formação ferrífera.

Não se observa estratificação bem definida, no entanto, pode-se definir bandas métricas com maior ou menor concentração de seixos e uma redução no tamanho destes, no contato entre bandas. Localmente, identificam-se corpos alongados de quartzitos, com poucos metros de extensão vertical e horizontal.

Em direção ao topo do pacote, ocorre diminuição no tamanho e na quantidade de seixos contidos na matriz, indicando uma passagem gradacional para a unidade superior do Grupo Ibiá.

A matriz da rocha é constituída por clorita, sericita/ muscovita, carbonato e quartzo de granulometria fina, exibindo fenoclastos de quartzo, plagioclásico, feldspato-potássico, calcita, chert, quartzito e calcário. Os clastos de feldspatos apresentam-se sericitizados e alguns clastos de plagioclásio estão saussuritizados. Os minerais acessórios são opacos, zircão, turmalina e rutilo, geralmente detríticos. Algumas vezes são observados cristais euédricos, neo-formados, de pirita e turmalina.

O metamofismo indicado pela paragênese sericita/ muscovita + clorita + quartzo + turmalina + pirita, é do tipo regional de baixo grau, na fácies xisto verde, zona da clorita.

\section{Formação Rio Verde}

Sobre o meta-paraconglomerado repousa extenso e monótono pacote de calcifilitos, formado por bandas

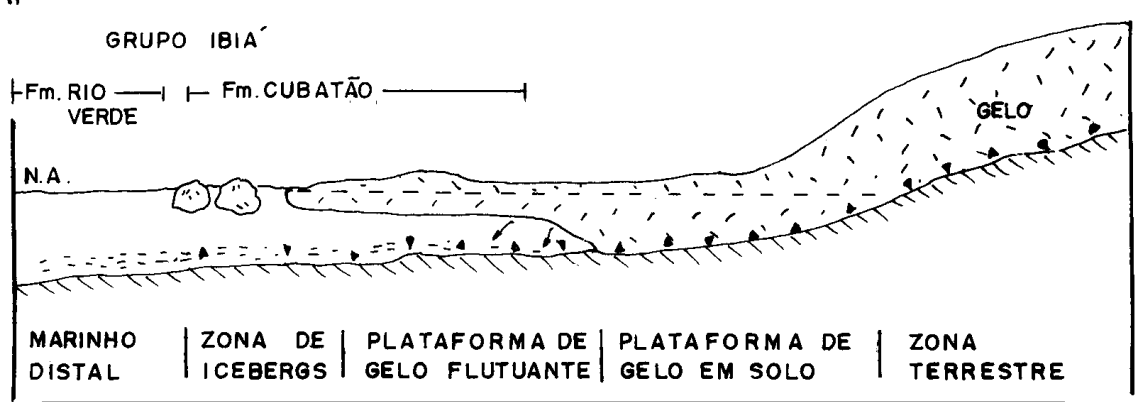

Figura 4: Modelo de ambiente de sedimentação para o Grupo Ibiá (modificado de Karfunkel \& Hoppe 1988).

Figure 4: Conceptual and schematic model of sedimentary environment of the Ibiá Group (modified after Karfunkel \& Hoppe 1988). centimétricas e rítmicas, quartzosas e micáceas, que constituem a Formação Rio Verde. Boas exposições encontram-se ao longo da calha deste rio. Entretanto, o estado avançado de intemperismo em quase toda a área desta formação e a deformação regional dificultam uma avaliação mais precisa de sua espessura real que, em termos gerais, deve situar-se em torno dos $1000 \mathrm{~m}$.

O contato basal do calcifilito com o metaparaconglomerado da Formação Cubatão é gradacional. Em lâmina delgada é nitida esta gradação, pois os filitos, na zona de contato, exibem fenoclastos que se tornam mais raros ao se afastar dela, passando ao calcifilito típico, finamente bandado.

Mineralogicamente, o calcifilito mostra-se semelhante à matriz do meta-paraconglomerado, sendo constituido, nas bandas micáceas, por clorita e sericita/ muscovita e nas bandas quartzosas, por quartzo fino e fenoclastos de quartzo, feldspato potássico, plagioclásio e calcita.

Além da ritmicidade composicional não são observadas outras estruturas sedimentares relíticas dentro desta sequência.

O contato superior da unidade não se encontra dentro do domínio da área mapeada mas, regionalmente, este se dá por falhamento de empurrão, que posiciona o Grupo Araxá sobre o Grupo Ibiá (Barbosa et al. 1970; Brod 1991). A espessura estimada dentro dos limites da área é superior a $1.000 \mathrm{~m}$.

Ambiente de Sedimentação

De acordo com a definição estabelecida por Frakes (1978, in Eyles et al. 1985), pode-se denominar o metaparaconglomerado da Formação Cubatão de metadiamictito. Seixos facetados, estriados, de composição e tamanhos muito variados, favorecem uma origem glaciogênica para o meta-diamictito.

Considerando as características identificadas no metadiamictito, o ambiente mais adequado à deposição da sequência, é o marinho plataformal, compreendido na faixa que se estende sob a plataforma de gelo até o marinho distal (Fig. 4)

Com base nos trabalhos desenvolvidos por Eyles et al. (1983) e Eyles (1988 e 1990), são esperadas para o metadiamictito condições de regime termal temperado, capaz de provocar fusão rápida da geleira gerando fluxo de detritos subaquoso. A ausência de gradação e de 
estratificação bem desenvolvidas indica fluxo coeso e laminar, percorrendo curtas distâncias e provavelmente resultante de escorregamento e remobilização de sedimentos instáveis.

Ainda segundo aqueles autores, bandas com maior e menor concentração de clastos são resultado da superposição de fluxos sucessivos. Os raros cordões de areia dentro do diamictito indicam retrabalhamento da superfície de fluxo, por correntes de tração.

Grande parte dos antigos depósitos glaciais conhecidos atualmente se formaram em ambientes de margem divergente, tipo margem atlântica, dominados por subsidência tectônica e grande potencial de preservação (Eyles et al. 1985). Outra categoria significativa de bacias glaciais inclui aquelas localizadas em ambiente cratônico. Ambos os tipos de bacia, comumente, apresentam margens de relevo baixo, implicando em área-fonte arrasada, gerando grande quantidade de material fino, com espessos mantos intempéricos, cujo principal, senão o único, agente erosivo atuante seria a própria geleira.

Esses dados reforçam os argumentos em favor de uma origem glacial para o metadiamictito da Formação Cubatão, que se encontra sobreposto às rochas do Grupo Canastra (originado em plataforma marinha continental) e sotoposto ao Grupo Bambuí (bacia epicratônica). A bacia de deposição Ibiá, provavelmente, apresentava baixa declividade, resultante da deposição anterior dos sedimentos do Grupo Canastra e caracterizava-se como um margem continental em subsidência progressiva, acarretando acumulação de grandes volumes de material.

\section{CORRELAÇÕES ESTRATIGRÁFICAS REGIONAIS}

A posição estratigráfica e a idade dos grupos Canastra e Ibiá, relativamente ao quadro regional, são determinadas pela correlação com outras unidades, uma vez que não existem datações radiométricas na região e que as relações de contato encontram-se mascaradas pela tectônica.

A unidade mais facilmente correlacionável é o Grupo Ibiá que, em função de suas características glaciogênicas, pode ser comparado à unidades de origem semelhante. No Brasil, são conhecidas diversas unidades glaciogênicas, depositadas no início do Proterozóico Superior e sotopostas ao Grupo Bambuí, constituindo um importante guia estratigráfico (Dardenne et al. 1978; Couto \& Bez 1981; Karfunkel \& Hoppe 1988; Gravenor et al. 1984) (Fig. 5). Estas unidades são:

- na borda leste do craton, o Grupo Macaúbas (Moraes 1929);

- na borda oeste, a Formação Topázio em Cristalina (Leonardos 1960), diamictitos de Nova Roma, Campos Belos, Boca da Lapa, Formosa-Cabeceiras e Padre Bernardo, na porção leste de Goiás (Barbosa et al. 1969 e Dardenne et al. 1978) e o tilito de Bezerra (Guimarães et al. 1986);

- a sudoeste do craton, a Sequência Carmo do Rio Claro (Heilbron et al. 1987).

Os dados geocronológicos existentes, obtidos em

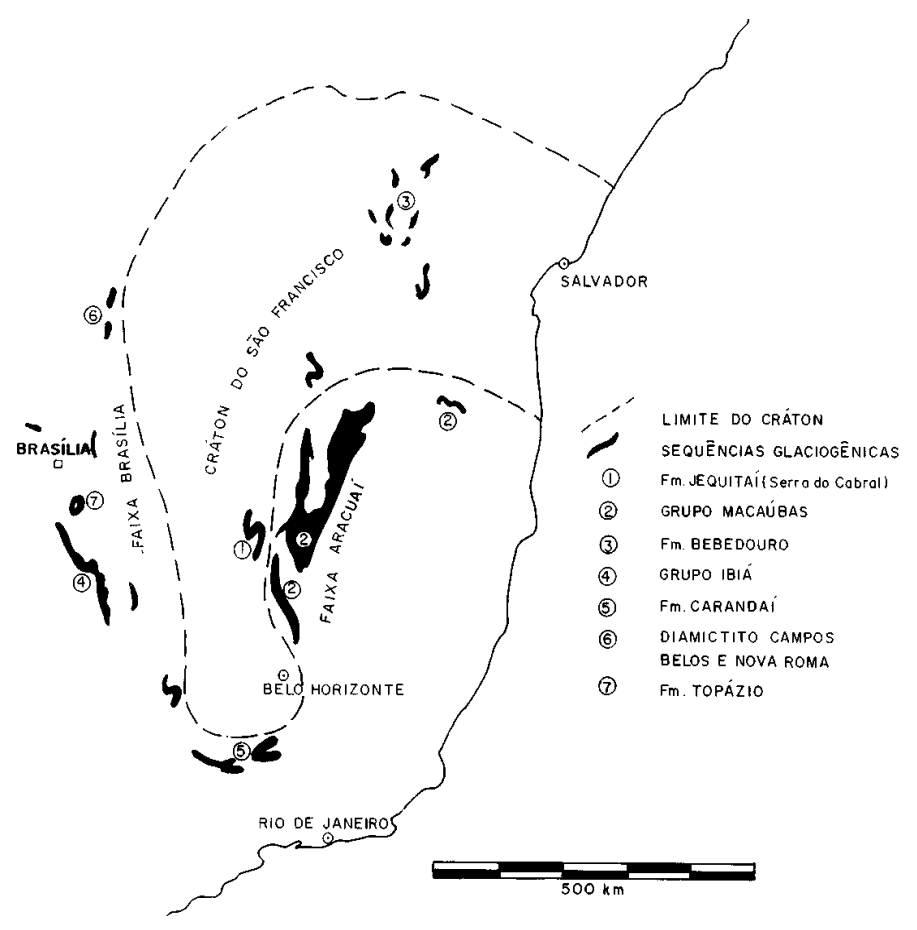

Figura 5: Sequências glaciogênicas neoproterozóicas no Craton do São Francisco e Faixas Marginais (modificado de Karfunkel \& Hoppe 1988).

Figure 5: Neoproterozoic glaciogenic sequences of the São Francisco craton and its marginal belts (modified after Karfunkel \& Hoppe 1988). 
rochas de unidades glaciogências, fornecem uma boa aproximação da idade deste período glacial. Alguns desses dados são:

- Bonhomme et al. (1982) e Macedo \& Bonhomme (1984) apresentam isócronas Rb-Sr e datações K-Ar em frações finas de sedimentos glaciogênicos da Formação Bebedouro, indicando estágios diagenéticos entre $960 \pm 31$ Ma e $876 \pm 20$ Ma.;

- Pedrosa-Soares et al. (1992) obtiveram idade Sm$\mathrm{Nd}$ em torno de $800 \mathrm{Ma}$ para rochas metabásicas da sequência vulcano-sedimentar intercalada na Formação Salinas e sugerem que esta unidade corresponda aos depósitos distais do Grupo Macaúbas, acumulados após o período glacial;

- Cloud \& Dardenne (1973) e Dardenne (1978 e 1981) estudando os estromatólitos das formações Vazante e Paracatu, sotopostas às unidades glaciogênicas, indicam idades entre 1350 e $950 \mathrm{Ma}$..

Avaliando-se este acervo geocronológico e as possibilidades de correlações regionais, pode-se considerar a Formação Cubatão (metadiamictito do Grupo Ibiá) mais antiga que $800 \mathrm{Ma}$., provavelmente depositada entre 900 e $1000 \mathrm{Ma}$, mostrando contemporaneidade com o Período Glacial Congo Inferior de Hambrey \& Harland (1985).

O Grupo Canastra, sotoposto ao Grupo Ibiá, tem, provavelmente, idade superior à $1000 \mathrm{Ma}$ e ocupa posição estratigráfica semelhante ao Grupo Paranoá, que também apresenta ciclos regressivos sotopostos à sequências glaciogênicas.

As relações dos grupos Canastra e Ibiá, sendo assim bem definidas, precisa-se considerar as suas respectivas relações com o Grupo Araxá. Para este propósito, um elemento importante a ser considerado consiste nas datações U-Pb de $794 \pm 10 \mathrm{Ma}$, obtidas por Pimentel et al. (1992) para as rochas vulcânicas ácidas intercaladas no Grupo Araxá, ao n orte da região estudada. Este dado sugere que pelo menos parte do Grupo Araxá foi depositado contemporâneamente ao Grupo Ibiá, ficando mais jovem que o Grupo Canastra, ao qual é tradicionalmente correlacionado na literatura geológica.

Neste sentido, torna-se possível sugerir, em função da datação obtida por Pedrosa-Soares et al. (1992) e das características petrográficas e sedimentológicas, uma contemporaneidade de deposição entre a Formação Salinas (Unidade Superior do Grupo Macaúbas, no nordeste de Minas Gerais, na borda leste do Cráton do São Francisco) e o Grupo Araxá.

\section{GEOLOGIA ESTRUTURAL}

Dois diferentes domínios estruturais (Fig. 6) foram individualizados na área: um ao sul, de maior deformação e outro ao norte, de menor deformação. Os elementos geométricos identificados foram englobados em um único evento de deformação progressiva $\left(\mathrm{E}_{1}\right)$, com individualização de dois estágios compressivos distintos (Tabela 1). O primeiro e mais expressivo estágio $\left(\mathrm{D}_{1}\right)$, representa deformação com forte componente de cisalhamento simples, em condições dúcteis, sendo responsável pelo desenvolvimento de estruturas típicas e zona de cisalhamento e pela falha de cavalgamento que superpõe os grupos Canastra e Ibiá à unidade VazanteParacatu. Ao final deste estágio ( $\mathrm{D}_{1}$-tardio), desenvolveu-se uma fase de dobramentos responsável pela geração de dobras em diversos estilos e escalas, com eixos variados e vergência geral para leste. Um outro estágio compressivo, agora caracterizado por um componente maior de cisalhamento puro $\left(\mathrm{D}_{2}\right)$, em condições dúcteis-rúpteis, produziu kink bands e tension gashes em pares conjugados de zonas de cisalhamento, uma clivagem de crenulação pervasiva e algumas dobras mesoscópicas simétricas. As clivagens de fratura e lineamentos estruturais identificados apresentam-se em pares conjugados, mostrando afinidade com o sistema de tensões registrado em $\mathrm{D}_{2}$ e portanto, estes elementos rúpteis foram, pelo menos em parte, associados ao final deste estágio. Posteriormente, durante o Cretáceo, toda a área foi afetada pela tectônica do soerguimento Alto Paranaíba, reativando diversas estruturas.

\section{Estágio de Deformação $D_{1}$}

$\mathrm{O}$ estágio $\mathrm{D}_{1}$ é caracterizado por tectônica de cavalgamentos, na qual desenvolveram-se zonas de cisalhamento desde centimétricas até poucas centenas de metros, com formação de foliação milonítica, lineação de estiramento, dobras isoclinais e dobras em bainha.

A estrutura principal gerada durante este estágio é a falha de cavalgamento, (denominada Falha de Coromandel), cujo bloco de teto é constituído pelos Grupo Canastra e Ibiá, apresentando alinhamento grosseiramente NS com traçado irregular. Caracterizase, no DOMÍNIO SUL, como uma rampa obliqua, mergulhando para oeste, com transporte de massa de SW para NE, o que coloca todo o bloco diretamente sobre as rochas da Formação Vazante. No DOMÍNIO NORTE, a alta obliquidade (rakes $\sim 90^{\circ}$ ) da lineação no plano da foliação sugere uma rampa da cavalgamento frontal e o bloco de teto está posicionado sobre as rochas da Formação Paracatu, indicando menor deslocamento.

A superfície planar de maior evidência, no DOMÍNIO SUL, está representada por uma foliação Sm, penetrativa, plano axial de dobras isoclinais intrafoliais, de orientação paralela a sub-paralela à estratificação original, com feições de milonitização como anastomosamento tipo S-C (Lister \& Snoke, 1984), foliation fish (Hanmer, 1986), nódulos sigmoidais de quartzo de veio e lineação de estiramento mineral. No DOMÍNIO NORTE, a principal anisotropia planar secundária, caracteriza-se como uma clivagem ardosiana, às vezes paralela ao plano estratigráfico, contendo lineação de minerais micáceos.

As dobras geradas neste estágio de deformação, com 


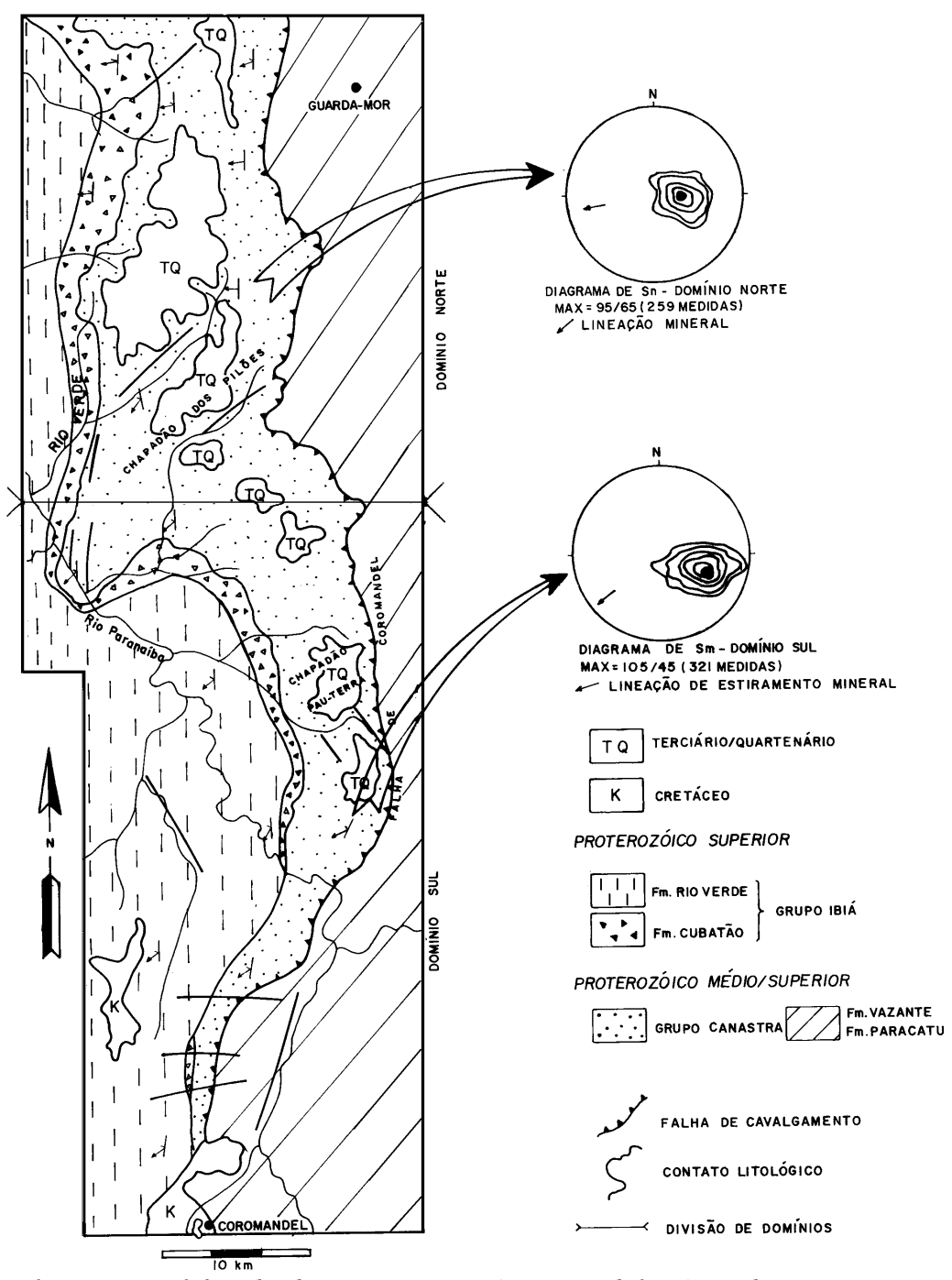

Figura 6: Mapa geológico simplificado da região entre Coromandel e Guarda-Mor e estereogramas sinópticos da foliação e lineação mineral nela contida.

Figure 6: Simplified geologic map of the region comprised between Cormandel and Guarda-Mor, and stereograms of its foliation and mineral lineation.

registro apenas nas rochas do DOMINIO SUL, são raras, recumbentes ou próximas a recumbentes, tendo a foliação milonítica como plano axial e com dimensões decimétricas a métricas. Localmente, sobre os quartzitos do Grupo Canastra, ocorrem dobras em bainha (Carreiras et al. 1977), decimétricas, com foliação milonítica plano axial e alongamento paralelo à lineação de estiramento do quartzo.

Os principais elementos cinemáticos mesoscópicos, identificados largamente no DOMÍNIO SUL e, localmente, no DOMÍNIO NORTE, são a foliação S$\mathrm{C}$, as zonas de cisalhamento centimétricas, a foliation fish, os sigmóides de quartzo, as dobras isoclinais e dobras em bainha, no Grupo Canastra e sombras de pressão e seixos estirados no Grupo Ibiá. Estatisticamente, os elementos registram movimentação dextral, com sentido do movimento de sudoeste para nordeste.

\section{Estágio de Deformação $D_{2}$}

O estágio $\mathrm{D}_{2}$ atinge os DOMÍNIOS NORTE e SUL com igual intensidade e é caracterizado por uma mudança no estilo e nas condições da deformação. $\mathrm{O}$ processo de deformação que mais se aproxima é o de cisalhamento puro, coaxial, em domínio dúctil a dúctilrúptil, com encurtamento na direção E-W, gerando estruturas simétricas e em pares conjugados.

Algumas das estruturas geradas durante este estágio são as kink bands conjugadas, dobras em chevron, clivagens de crenulação e zonas de cisalhamento conjugadas apresentando fissuras extensionais (tension gashes) em arranjo escalonado. Todas estas estruturas mostram a mesma relação dos eixos dos elipsóides de tensão e deformação.

\section{EVOLUÇÃO GEOLÓGICA}

O Grupo Canastra apresenta-se como uma megasequência regressiva depositada em plataforma continental de mar aberto, na qual sucedem-se, da base para o topo, estratos típicos de ambientes cada vez mais rasos. A unidade inicia com uma sequência turbidítica, formada por fluxos alternados de areia e argila, indicando bacia de declividade elevada em ambiente 


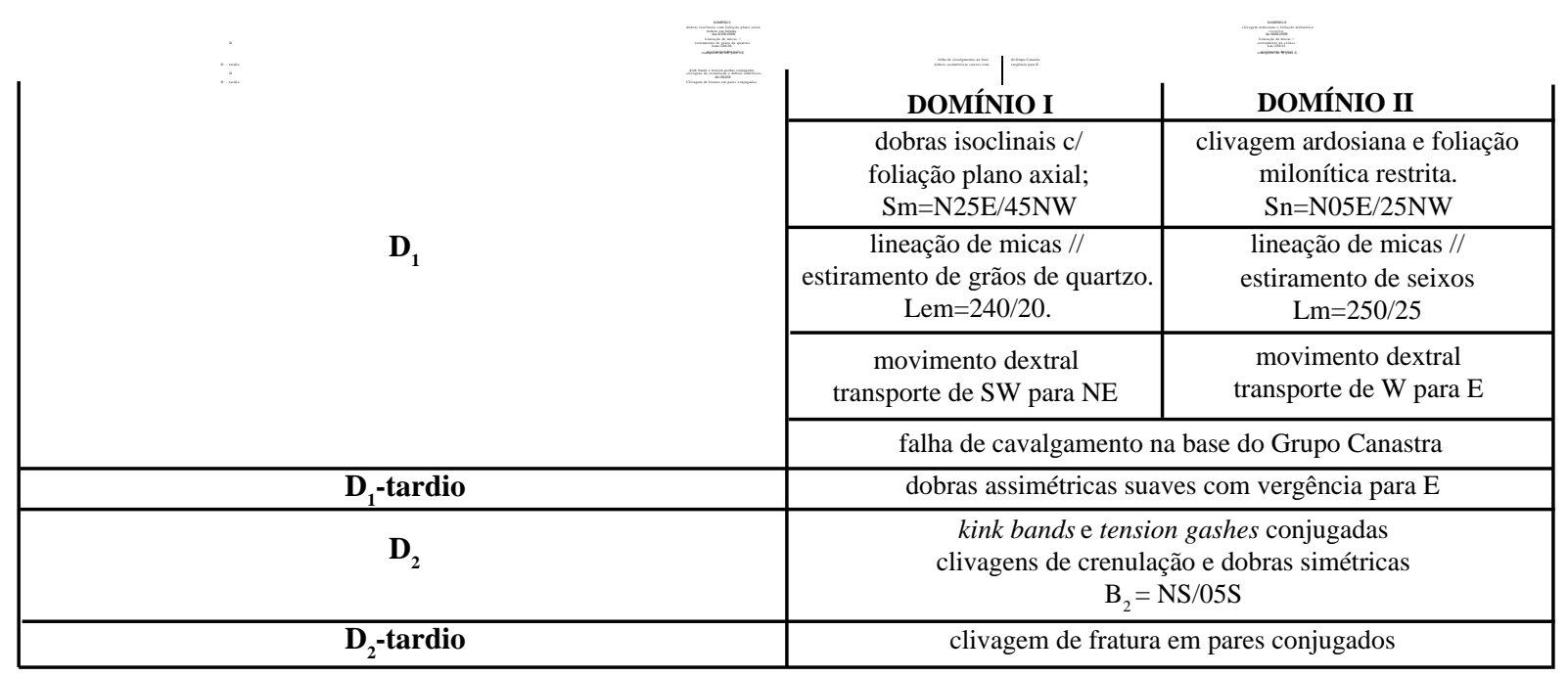

Tabela 1: Síntese dos dados estruturais associados ao Evento E1.

de mar profundo. Sobre os turbiditos deposita-se sequência arenosa alcançada pela ação de ondas provocadas por tempestades, gerando estratificações cruzadas tipo hummocky. Finalizando o ciclo regressivo, ocorre sedimentação característica de ambiente marinho raso, passando a planície de maré, com registro nos estratos areno-argilosos que contêm estratificações cruzadas tabulares e laminações flaser.

Segue-se um período glacial, cujas geleiras, oriundas de um continente intensamente erodido (correspondente ao Craton do São Francisco) posicionado à leste da bacia, contribuiram com o aporte de grande volume de sedimentos finos e grosseiros à uma bacia rasa, entulhada pela deposição anterior do Grupo Canastra.

A identificação de estruturas do tipo hummocky e laminações flaser, permitem avançar no modelo de Campos Neto (1979, 1984), favorecendo um modelo deposicional de ciclo marinho regressivo.

Esta proposta evolutiva é comparável à evolução do Grupo Paranoá que apresenta contemporaneidade sedimentar e está sotoposto à sequências glaciogênicas (Dardenne, 1978, 1981a). As duas sequências apresentam ciclos regressivos, diferenciados pela paleogeografia interna de cada bacia.

Os sedimentos glaciogênicos que recobrem os metassedimentos do Grupo Canastra, aqui representados pelo Grupo Ibiá, estão relacionados à Glaciação Jequitaí, constituindo, juntamente com outras unidades das mesmas características, um importante guia estratigráfico nas coberturas do Craton do São Francisco e nas faixas marginais (Dardenne 1979, Dardenne et al. 1978, Couto \& Bez 1981, Gravenor et al. 1984, Karfunkel \& Hoppe 1988). Esta glaciação integra a era glacial da base do Proterozóico Superior, com registro em quase todos os continentes e estabelece um limite para a idade mínima do Grupo Canastra e sequências correlatas. Os dados geocronológicos apontam uma idade para a glaciação no intervalo 1000 - $900 \mathrm{Ma}$.

A deformação registrada nas rochas dos grupos
Canastra e Ibiá, sistematizada no evento $\mathrm{E}_{1}$, corresponde ao Evento Brasiliano e resulta do esforço compressivo de fechamento da bacia, que provocou a estruturação de toda a Faixa de Dobramento Brasília, na forma de lascas empurradas de encontro ao Craton do São Francisco.

O primeiro estágio de deformação $D_{1}$ é caracterizado por tectônica de cavalgamentos, que sobrepõe os grupos Canastra e Ibiá à Unidade ParacatuVazante, desenvolvendo zonas de cisalhamento e diversas estruturas associadas. As principais estruturas geradas são a foliação milonítica paralela à estratificação original, de direção NNE e uma lineação de estiramento mineral e de seixos com obliquidade (rake) de aproximadamente $30^{\circ}$ no Domínio Sul e entre $70^{\circ}-90^{\circ}$ no Domínio Norte. As diferentes obliquidades evidenciam movimentos dominantemente frontais no Domínio Norte, mas oblíquos no Domínio Sul. O metamorfismo regional, de fáceis xisto-verde é contemporâneo ao estágio $\mathrm{D}_{1}$.

Após a estruturação da falha de cavalgamento (Falha de Coromandel), o sistema de tensões $\mathrm{D}_{1}$ permanceu ativo, gerando dobras assimétricas tipo flanco longo-flanco curto, com vergência geral no sentido leste (estágio $\mathrm{D}_{1}$-tardio). Alguns eixos de dobras, juntamente com algumas lineações do estágio $\mathrm{D}_{1}$, foram rotacionados em função do movimento diferenciado da frente de empurrão.

Uma mudança no estilo e nas condições de deformação marcam a passagem para o estágio $\mathrm{D}_{2}$. A deformação é coaxial, em domínio dúctil a dúctil-rúptil, aproximando-se do modelo de cisalhamento puro, com encurtamento na direção leste-oeste. São geradas estruturas simétricas em pares conjugados de zonas de cisalhamento, do tipo kink bands e tension gashes, que permitiram determinar o posicionamento dos elipsóide de deformação e tensão. Ainda neste estágio são gerados crenulação e dobramento tipo chevron, de planos axiais de direção NS, verticais, que contêm a bissetriz do ângulo agudo, formado pelos pares conjugados de kink band e tension gashes. 
Finalizando a deformação brasiliana, já em condições francamente rúpteis e de alívio das tensões compressivas coaxiais, são formados sistemas conjugados de juntas de cisalhamento. Estes sistemas são, aproximadamente, superpostos aos conjugados $\mathrm{D}_{2}$ e por isso são relacionadas ao final deste estágio. Estas estruturas podem ser observadas tanto em escala de afloramento, quanto em fotolineamentos regionais.

A espessura reduzida do Grupo Canastra no Domínio Sul, juntamente com a maior intensidade da deformação no estágio $\mathrm{D}_{1}$ e o contato direto sobre a Formação Vazante, suprimindo a Formação Paracatu, sugerem que o Grupo Canastra, neste domínio, foi transportado através de uma extensão maior com relação ao Domínio Norte. Tal observação pode traduzir, também, a presença de um alto do embasamento, posicionado mais a leste, resultando numa compressão maior nesta área.

Como foi descrito anteriormente, as relações dos grupos Canastra e Ibiá são claras, demonstrando que o Grupo Ibiá se sobrepõe em discordância erosiva ao Grupo Canastra e que os dois grupos foram envolvidos na mesma evolução deformacional do Ciclo Brasiliano. Os dados geocronológicos até agora disponíveis favorecem a hipótese de contemporaneidade de deposição dos grupos Ibiá e Araxá, permitindo assim aventar uma evolução paralela a da Formação Salinas e do Grupo Macaúbas, pertencentes à Faixa Araçuaí, na borda leste do Craton do São Francisco.

\section{REFERÊNCIAS BIBLIOGRÁFICAS}

ALMEIDA, F.F.M.; HASUI, Y. - 1968 - Evolução tectôncia do Centro Oeste Brasileiro no Proterozóico Superior. An. Acad. Bras. Ciên. 40 (Suplemento): 285-295.

ALMEIDA, F.F.M. - 1977 - O Craton do São Francisco. Rev. Bras. Geoc., 7(4): 349-364.

ALMEIDA, F.F.M.; HASUI, Y.; BRITO NEVES, B.B. - 1976 - The upper Precambrian of South America. Bol. Inst. Geoc., USP, 7: 45-80.

ALMEIDA, F.F.M.; HASUI, Y.; BRITO NEVES, B.B., FUCK, R.A. - 1977 - Províncias estruturais brasileiras. In: SIMP. GEOL. NORD., 8. Campina Grande, 1977. Atas... Campina Grande, SBG/NE. p. 363-391.

BARBOSA, O. - 1955 - Guia de excursões. In: CONGR. BRAS. GEOL., 9. Araxá. Noticiário, 3: 3-5. SBG, São Paulo.

BARBOSA, O.; BATISTA, M.B.; DYER, R.C.; BRAUN, O.P.C.; COTTA, J.C. - 1969-Geologia e inventário de recursos minerais do Projeto Brasília. Rio de Janeiro. DNPM/PROSPEC (inédito).

BARBOSA, O.; BRAUN, O.P.C.; DYER, R.C.; CUNHA, C.A.B.R. - 1970 - Geologia da região do Triângulo Mineiro. Rio de Janeiro. DNPM/DFPM. 140p. (Boletim 136).

BONHOMME, M.G.; CORDANI, U.G.; KAWASHITA, K.; MACEDO, M.H.F.; THOMAZ-FILHO, A. - 1982 Radiochronological age correlation of sediments in Brazil. Precambrian Research 18, 103-118.

BRANCO, J.J.R. - 1957 - O conglomerado Samburá, Minas Gerais, An. Acad. Bras. Ciên. Rio de Janeiro. 28(3): 295-301.

BRITO-NEVES, B.B \& CORDANI, U.G. - 1991 - Tectonic evolution of South America during the Late Proterozoic. Precambriam Research, 53: 23-40.

BROD, J.A. - 1991 - Tectono-estratigrafia da Faixa Brasília na região do Alto Paranaíba. In: SIMP. GEOL.CENTRO OESTE, 3. Goiânia,1991. Anais...Goiânia, SBG/Centro Oeste, p.155-168.

CAMPOS NETO, M.C. - 1979 - Contribution à l'etude des Brasilides: Lithostratigraphie et structure des groupes Canastra,
Paranoá et Bambuí dans l'Ouest - Nord-Ouest de l'état de Minas Gerais (Brésil). Tese de doutoramento. Univ. Pierre et Marie Curie. Paris VI. Dept. Geotectonique, 155p. (inédita).

CAMPOS NETO, M.C. - 1984 - Litoestratigrafia e evolução paleogeográfica dos Grupos Canastra e Paranoá (Região VazanteLagamar, MG). Rev. Bras. Geoc., 14(2): 81-91.

CARREIRAS, J.; ESTRADA, A.; WHITE, S.H. - 1977 - The effects of folding on the c-axis fabrics of quartz mylonite. Tectonoph., 39: 3-24.

CHEMALE JR., F.; ALKMIM, F.F.; ENDO, I. - 1991 - Late tectonism in the interior of São Francisco Craton. In: INT. SYMP. ON GONDWANA, 8. Austrália, 1991. (No prelo).

CLOUD, P.E. \& DARDENNE, M.A. - 1973 - Proterozóic age of Bambuí Group in Brazil. Geol. Soc. Am., Bull. 84: 1673-1676.

CORDANI, U.G. \& BRITO NEVES, B.B. - 1982 - The geologic evolution of South America during the Archean and Early Proterozoic. Rev. Bras. Geoc.,12(1/3): 305-312.

COSTA, L.A.M. \& ANGEIRAS, A.G. - 1971 - Geosynclinal evolution of the Epi-Baykalian Plataforma of Central Brazil. Geol. Rundschau, 60(3): 1024-1050.

COUTO, J.G.P. \& BEZ, L. - 1981 - A glaciação Jequitaí: um guia estratigráfico para o Pré-Cambriano Superior no Brasil.Rev. Bras. Geoc., 11(1): 17-21.

CRAFT, J.H. \& BRIDGE, J.S. - 1987 - Shallow-marine sedimentary process in the Late Devonian Catskill Sea, New York State. Geol. Soc. Amer., Bull, 98: 338-355.

DARDENNE, M.A. - 1978 - Zonação tectôncia da borda ocidental do craton do São Francisco. In: CONGR. BRAS. GEOL., 30, Recife, 1978, Anais... Recife, SBG. V. 1, p. 299-308.

DARDENNE, M.A. - 1979 - Les mineralisations de plomb, zinc, fluor du Protérozoique Superieur dans le Brésil Central.Thése de Doutorat d'Etat, Université de Paris VI, 251p, (inédito).

DARDENNE, M.A. - 1981 - Os grupos Paranoá e Bambuí na Faixa Dobrada Brasília. In: SIMP. SOBRE O CRATON DO SÃO FRANCISCO E SUAS FAIXAS MARGINAIS. Salvador, 1981. Anais... Salvador, SBG/BA. p.140-156.

DARDENNE, M.A.; FARIA, A.; MAGALHÃES, L.F.; SOARES, L.A. - 1978 - O tilito da base do Grupo Bambuí na borda ocidental do craton São Francisco. SBG/ Goiânia, Bol. Inf. 7/8: 85-97.

DUKE, W.L. - 1985 - Hummocky cross-stratification, tropical hurricanes and intense winter storms. Sediment., 32: 168-194.

EYLES, N.; EYLES, C.; MILL, A.D. - 1983 - Lithofacies types and vertical profile models; an alternative approach to the description and environmental interpretation of glacial diamict and diamictite. Sedimentology, 30: 393-410.

EYLES, C.; EYLES, N.; MIALL, A.D. - 1985 - Models of glaciomarine sedimentation and their application to the interpretation of ancient glacial sequences. Paleog., Paleocl., Paleoec., 51: 15-84.

EYLES, N. - 1988 - Glacially- and tidally -influenced shallow marine sedimentation of Late Precambrian Port Askaig Formation, Scotland. Paleog., Paleocl., Paleoec., 68: 1-25.

EYLES, N. - 1990 - Marine debris flows: Late Precambrian "tilites" of the Avalonian-Cadomian orogenic belt. Paleog., Paleocl., Paleoec., 79: 73-98.

FRAKES, L.A. - 1978 - Diamictite. Encyclopedia of sedimentology. In: EYLES, C.; EYLES, N.; MIALL, A.D. - 1985 - Models of glaciomarine sedimentation and their application to the interpretation of ancient glacial sequences. Paleog., Paleocl., Paleocl., 51: 15-84.

FUCK, R.A. \& MARINI, O.J. - 1981 - O Grupo Araxá e unidades homotaxiais. In: SIMP. SOBRE O CRATON DO SÃO FRANCISCO E SUAS FAIXAS MARGINAIS. Salvador, 1981. Anais... Salvador, SBG/BA. p. 118-130.

GRAVENOR, C.P.; VON BRUNN, V; DREIMANIS, A. - 1984 Nature and classification of waterlain glaciogenic sediments, exemplified by Pleistocene, Late Proterozoic and Late Precambrian Deposits. Earth Science Reviews, 20: 105-166.

GUIMARÃES, E.M.; DARDENNE, M.A.; FARIA, A.; COELHO, C.E.S.; PLAVILINO, P.O.V. - 1986 - Relações dos grupos Jequitaí e Bambuí na região de Bezerra, GO. IN: CONG. BRAS. 
GEOL., 34. Goiânia, 1986. Anais... Goiânia, SBG., V. 1, p. 835860.

HAMBREY, M.J. \& HARLAND, W.B. - 1985 - The Late Proterozóic Glacial Era. Paleog., Paleocl., Paleoec., 51: 255-272.

HANMER, S. - 1986 - Asymmetrical pull-aparts and foliation fish as kinematic indicator. J. Struct. Geol., 8(2): 111-122.

HARALY, N.L.E. \& HASUI, Y. - 1982 - Compartimentação geotectônica do Brasil Oriental com base na informação geofísica. In: CONGR. BRAS. GEOL., 32. Salvador, 1982. Anais... Salvador, SBG, V. 1, p. 374-385.

HARMS, J.C.; SOUTHARD, J.B.; WALKER, R.G. - 1982 Structures and sequences in clastic rocks: Calgary. Soc. Econ. Paleont. Mineralogists, Short Course, V. 9. 249p.

HASUI, Y. \& ALMEIDA, F.F.M. - 1970 - Geocronologia do Centro Oeste Brasileiro. Bol. Soc. Bras. Geol., 19(1): 7-26.

HEILBRON, M.H.; VALERIANO, C.M.; ZIMBRES,E.; CHRISPIM, S.J; SIMÕES, A.; SOUZA, M.A.T. - 1987 - O contato basal do Grupo Canastra entre Itaú de Minas e Carmo do Rio Claro, MG. In: SIMP. GEOL. MINAS GERAIS, 4. Belo Horizonte, 1987. Anais... Belo Horizonte, SBG/MG. Bol. 6, p. 176-198.

KARFUNKEL, J. \& HOPPE, A. - 1988 - Late Proterozoic glaciation in central-eastern Brazil: Synthesis and models. Paleog., Paleocl., Paleoec., 65: 1-21.

LEONARDOS, O.H. - 1960 - Observações geológicas em Cristalina, Goiás. Eng. Min. Metal. Rio de Janeiro. 31(185): 217-224.

LISTER, G.S. \& SNOKE, A.W. - 1984 - SC Mylonites. J. Strut. Geol., 6(6): 617-638.

MACEDO, M.H.F. \& BONHOMME, M.G. - 1984 - Contribuição à cronoestratigrafia das formações Cabloco, Bebedouro e Salitre na Chapada Diamantina (BA) pelos métodos Rb-Sr e K-Ar. Rev. Bras. Geoc. 14(3): 153-163.

MARINI, O.J.; FUCK, R.A.; DANNI, J.C. - 1981 - A evolução geotectônica da Faixa Brasília e seu embasamento. In: SIMP. SOBRE O CRATON DO SÃO FRANCISCO E SUAS FAIXAS MARGINAIS. Salvador, 1981. Anais... Salvador, SBG/BA. p. 100-113.

MARINI, O.J.; FUCK, R.A.; DANNI, J.C.; DARDENNE, M.A.; LOGUERCIO, S.O.; RAMALHO, R. - 1984 - As faixas de dobramento Brasília, Uruaçu e Paraguai-Araguaia e o Maciço Mediano de Goiás. In: SCHOBBENHAUS, C,; DIÓGENES, A.C.; DERGE, G.R.; ASMOS, M.G. (Coord.) 1984. Geologia do Brasil. Brasília. DNPM. p. 251-303.

MORAES, L.J. DE - 1929 - Geologia da Região de Diamantina, Minas Geraes. Rel. An. Dir. do Serv. Geol. e Min., (1928):29-34.

PEDROSA-SOARES, A.C.; NOCE, C.M.; VIDAL, Ph.; MONTEIRO, R.; LEONARIDOS, O.H. - 1992 - Toward a new tectonic model for the Late Proterozoic Araçuaí (SE Brazil) West Congolian (SW Africa) Belt. Journal of South American Earth Sc., 6 (1/2): 33-47.

PEREIRA, L.F. - 1992 - Relações Tectôno-estratigráficas entre as unidades Canastra e Ibiá na região de Coromandel, MG. Dissertação de mestrado. Brasília. UnB, Inst. Geoc. 75p. (inédita).

PETRI, S.; COIMBRA, A.M.; AMARAL, G.; OJEDA y OJEDA, H.A.; FÚLFARO, V.J.; POÇANO, W.L. - 1986 - Código Brasileiro de Nomenclatura Estratigráfica/ Guia de Nomenclatura Estratigráfica. Rev. Bras. Geol., SBG, 46p.

PIMENTEL, M.M.; HEAMAN, L.; FUCK, R.A. - 1992 - Idade do meta- riolito da sequência Maratá, Grupo Araxá, Goiás: Estudo geocronológico pelos métodos U-Pb em zircão, $\mathrm{Rb}-\mathrm{Sr}$ e SmNd. An. Acad. Bras. Ciênc., 64(1): 19-28.

REINECK, H.E. \& SINGH, I.B. - 1973 - Depositional sedimentary enviroments. Berlin, Springer-Verlag. 439 p.

WALKER, R.G. - 1984 - Facies models (second edition), Geosciences Canada, Reprint Series 1, 317 p. 